Fecha de recepción: marzo 2010 Fecha de aceptación: marzo 2011 Versión final: septiembre 2013

\section{La importancia de la comunicación en el marketing interno}

Alejandro Prats *

\begin{abstract}
Resumen: Cuando pensamos en términos de lo que para una empresa implica la capacitación del personal que la compone aparecen más dudas que certezas. Encontrar a los profesionales adecuados, en qué momento o época del año es más factible destinar tiempo para formar a nuestra gente y que esto no implique una baja en la rentabilidad de la empresa debido a que los empleados no están en sus puestos de trabajo como lo hacen normalmente, cuanto se deberá invertir para ello, etc. Son cuestiones que los gerentes de las empresas deben planificar en una vorágine que los abstrae y concentra ferozmente alejándolos de la toma de decisiones. Pues bien, conjuntamente con estas cuestiones, surge la idea de realizar un trabajo de marketing interno, puertas hacia dentro. Es hora de indagar, conocer, profundizar y poner en práctica aquellos valores, virtudes, aciertos, fortalezas y porque no también desventajas que tiene la empresa. Las cuales se deberán trabajar para revertir y convertirlas en aspectos positivos.
\end{abstract}

Palabras claves: capacitación del personal - comunicación interna - diferenciación - endomarketing - gestión de las actitudes - imagen e identidad corporativa - intereses individuales y grupales - plan de comunicación - rol del líder.

[Resúmenes en inglés y portugués en las páginas 248-249]

(*) Licenciado en Ciencias de la Comunicación (UBA), especialidad en Marketing, Comunicación y Consultoría empresarial. Docente de la Universidad de Palermo en el Departamento de Negocios en Diseño y Comunicación de la Facultad de Diseño y Comunicación.

\title{
Introducción
}

Toda organización que se precie de tal debe trabajar sobre sus propios cimientos, para ello una de las premisas que no pueden evadirse es el tratamiento de la comunicación interna dentro de la empresa, establecer el plan de comunicación para transmitir políticas, objetivos y acciones. $\mathrm{Si}$ la empresa u organización comprende que su primer cliente es su empleado y que la comunicación que lleve adelante para él y con él es de vital importancia tendrá un gran paso dado hacia la concreción de obtener óptimos resultados, dando lugar así a un proceso de trabajo donde se logren las ideas, objetivos y políticas establecidas inicialmente.

El papel que desarrollan los empleados dentro de las empresas es primordial para poder alcanzar el éxito pero sucede que observando la casuística que se nos presenta a diario pareciera que 
esta idea es algo que se da por sentado, es algo que se dice pero en realidad ¿̇e piensa? Los empresarios, los altos mandos y directivos de las empresas ¿comprenden verdaderamente el rol de las personas dentro de las organizaciones? ¿Asimilan que son vínculos que se entrelazan no sólo desde lo laboral sino también desde lo afectivo, lo emocional? Entrando en juego las emociones y percepciones, sensaciones, miedos, dudas, certezas...Para trabajar la idea de la comunicación dentro de las organizaciones es necesario profundizar la manera en que se comportan las personas en la vida cotidiana.

Para ello se hará referencia a los conceptos vertidos por Erving Goffman en su libro Actuaciones, la presentación de la persona en la vida cotidiana. Goffman (1994) refiere en este texto a la confianza que tiene cada individuo en el papel que desempeña en y ante una sociedad determinada. Da cuenta que cuando un individuo lleva adelante un papel está pidiendo a sus observadores que tomen como verdadero la imagen que se da ante ellos. En este artículo se abordará el tratamiento de la comunicación interna en una organización partiendo de la noción de que toda acción individual debe ser insertada en una sociedad, por lo tanto el comportamiento de las personas dentro de las empresas debe ser tratado como todo acto comunicativo que se produce entre varios individuos con diferentes personalidades, sensaciones y pensamientos pero con un sólo fin en común al pertenecer a una organización o empresa determinada: la búsqueda del cumplimiento de los objetivos trazados y establecidos por la empresa.

Siguiendo esta línea de pensamiento Goffman (1994) manifiesta:

...en el acto comunicativo se produce una interacción entre varios individuos, interacción que se da en el orden de lo simbólico que construye las diversas instancias de las redes sociales. Cuando se concibe la comunicación como actividad social, se coloca un mecanismo de orden superior por encima de la comunicación (inter)individual. Cada acto de transmisión de mensaje se integra a una matriz mucho más vasta. Esta matriz, que recibe el tan vapuleado nombre de comunicación social, constituye el conjunto de los códigos y las reglas que hacen posible y mantienen en la regularidad y la previsibilidad las interacciones y las relaciones entre los miembros de una misma cultura. Así concebida, la comunicación en la sociedad es pues permanente: no se sostiene en la acción de un individuo, aquella que remite linealmente a un mensaje emitido y/o decodificado; más claramente, permite que la acción individual se inserte en una continuidad. El individuo es visto como un "actor social", como un participante de una entidad que lo subsume. Las actividades comunicativas son actividades de control, de confirmación, de "integración", donde la redundancia juega un papel importante. (Goffman, 1994, p.46).

Una organización contiene una determinada cultura, por eso los miembros deben recibir un mensaje claro, específico y que tenga sentido entre todos los que conforman la empresa. El endomarketing debe estar signado por una comunicación que desde la Dirección de la empresa refleje una estrategia. Entonces será necesario pensar y encuadrar la política de comunicación interna a seguir. Por eso tomando las palabras expresadas en el párrafo anterior por 
Goffman entendemos el accionar comunicativo como actividad de control, pero también de confirmación y de integración dentro de una organización. La verdadera integración se logrará si aquello que se transmite al personal como normativas, objetivos y necesidades se lleva acabo de manera clara, sin contradicciones ni pasos en falso. El accionar de cada individuo, que para nosotros será cada empleado, estará concatenado con el accionar del resto de sus compañeros dando sentido al funcionamiento de la empresa.

El autor también expresa:

la redundancia es uno de los mecanismos por los cuales se sostiene y se afirma el hilo de la comunicación. Se trata de enunciados verbales o de gestos que permiten la continuidad del acto comunicacional, por medio de la reiteración de conceptos o enunciados ya emitidos o de la explicitación aparentemente innecesaria de ideas implícitas en esa interacción (Goffman, 1994, p.47)

La existencia de reglas implícitas permite hablar de la noción de contrato, pacto o acuerdo de comunicación, también por lo general, implícito en el juego de la interacción. Para entender a que refiere un contrato de comunicación hay que recordar la diferenciación entre lo dicho (enunciado) y las modalidades del decir (enunciación), donde las modalidades del decir construyen el dispositivo de enunciación, a saber: la imagen del que habla, o sea, el enunciador; la imagen del destinatario del discurso; la relación entre enunciador y destinatario, que son entidades discursivas a las que hay que distinguir del emisor real y del receptor real. Todo soporte de interacción contiene su dispositivo de enunciación, al que se denomina contrato o pacto de comunicación. Es en este pacto en donde se dirimirá el compromiso que alcanzará cada integrante de una organización a la hora de llevar adelante sus tareas, siempre en contacto directo con el resto de sus compañeros y de la compañía. Es sabido que las mayores dificultades en las empresas se dan internamente cuando entre los diferentes sectores, secciones o departamentos de una organización determinada no logran hablar el mismo idioma, no comprenden que la cultura de la empresa debería ser la misma para todos. Esto se debe a que la comunicación desde la Dirección no ha sido bien implementada. Los mandos medios tienen un rol importante ya que deben transmitir la estrategia de la Dirección a seguir y si la misma no es bien transmitida surgen los ruidos en la comunicación. Y como sabemos esto repercute en el vínculo de los empleados y de las distintas áreas de trabajo. Sucediéndose una serie de incomunicaciones, inequívocos que siempre repercuten en el cliente externo, socavando la identidad y la imagen corporativa. Como consecuencia se ven afectados el cumplimiento del plan de negocios y la rentabilidad.

En estas épocas donde el rol del cliente es absolutamente activo, se debe entender que la capacitación constante para los empleados es decisiva. La información debe circular cuando así se lo desea por todos los sectores de la empresa para no generar quiebres entre los distintos sectores que a la hora de tratar con el cliente quedarán mal expuestos ante una demanda específica. Y esto tiene su punto de partida en la comunicación. Y más aún en la gestión de las actitudes. 


\section{La gestión de las actitudes y el rol del líder en las organizaciones}

En este apartado continuamos transitando el camino de la comunicación puertas adentro, el branding interno que posibilite traspasar con claridad y eficiencia el umbral de la empresa para llegar a cada cliente y lograr esa diferenciación que hará que una organización logre posicionarse por encima de otras. El valor que genere internamente será el que los ubicará en el mercado con una verdadera ventaja competitiva. Para lograrlo la organización debe contar con líderes capaces de realizar la tarea -nada sencilla por cierto- de bajar al personal los lineamientos fundamentales que han sido trazados por la Dirección de la empresa, su trabajo será establecer una comunicación fluida, inclusiva sobre todo. ¿Qué se quiere decir al mencionar la palabra inclusiva? Que se debe trabajar sobre todas las áreas de la empresa y con cada integrante. Cada individuo, cada empleado, como dijimos antes, está vinculado con otro, inserto en un sector y en una tarea que a su vez se vincula directamente o indirectamente con otros sectores. Para que estos funcionen a la hora del trabajo cotidiano y puedan lograr minimizar el grado de conflictividad, el líder deberá realizar una correcta y efectiva gestión de las actitudes. La manera en que los integrantes de una organización llevan adelante sus roles es y será vital. Y para ello la racionalidad discursiva y la actitud dialógica será necesaria para lograr unir intereses individuales con intereses grupales. Cuando se entabla una comunicación, en este caso podemos decir un diálogo es menester poder arribar a un entendimiento de índole universalista. Traspolándolo a nuestro objeto de análisis diremos que el entendimiento tiene que darse en beneficio de la organización. Siempre previamente gestionando las actitudes desde lo individual para llegar a lo general. Arribar a intereses de carácter universal, lo cual se relaciona con aquello que todos podrían llegar a querer como organización, como empresa. En este punto entendemos que radica el mayor de los conflictos dentro de las organizaciones a la hora de gestionar una correcta comunicación, muchas veces las empresas subestiman el rol de los líderes para con su gente. La acción comunicativa exacta entre un orador y sus interlocutores se vislumbra en pos del entendimiento mutuo del acuerdo tácito entre ambos. Que incluye el respeto, la solidaridad y la intención de permitirle al otro que se exprese y exponga sus razones. La percepción o intuición por parte del líder a la hora de construir su discurso, su verdad, en tanto esta represente la verdad de la empresa conlleva una responsabilidad sobre lo dicho. Responsabilidad que comienza cuando el líder debe escuchar las necesidades de la Dirección de la empresa, ponerlas en práctica al mismo momento que debe trasmitirlas a los empleados, con quien a su vez deberá tener una actitud de diálogo como ya expresamos anteriormente. Permitiendo así lograr una eficaz política de comunicación interna.

\section{Branding interno}

A la hora de pensar en promocionar los valores de la marca y la identidad e imagen corporativa de una compañía entre sus empleados como primer paso es pertinente profundizar en lo expresado en este escrito. Para comprender más sobre el tema introducimos a Kotler (1998) que presenta una reseña del manejo de las relaciones con los empleados de la cadena de hoteles Ritz- Carlton. 
Cuando se presenta con los nuevos empleados, el presidente del hotel dice: "Mi nombre es Horst Schulze. Soy el presidente y soy una persona muy importante aquí". Después de unos segundos, continúa: "Pero usted también lo es. De hecho, usted es más importante para los clientes que yo. Si usted no se presenta a trabajar, estamos en problemas. Si yo no me presento, creo que nadie lo notaría." Según Kotler "estos comentarios reflejan la actitud del señor Schulze y su pensamiento acerca de que los empleados son el componente decisivo en el servicio de la calidad. Por consiguiente, Ritz Carlton selecciona con mucho cuidado sólo a los aspirantes con actitud solícita apropiada. Por cada nuevo empleado en una sesión preliminar de orientación, otros 10 solicitaron el puesto, de modo que se dice que a los empleados que no fueron contratados, sino seleccionados. Una vez seleccionado, cada empleado aprende la cultura corporativa del hotel, con una extensa capacitación en el trabajo, que da como resultado la certificación del puesto. (Kotler, 1998, p. 600)

Esta cita nos permite observar de qué manera las corporaciones que piensan en sus empleados y su relación con ellos logran alcanzar los niveles de calidad buscados, el verdadero sentido de trabajo se debe buscar en el interior de la organización y la manera en que se trata, informa, estimula a su gente. Como menciona Kotler todo se vincula a la cultura corporativa, si verdaderamente se trabaja para capacitar al personal, si se implementan acciones concretas para sondear qué sucede con nuestros empleados en cada sector, área o departamento permitiendo que las necesidades, problemas e incertidumbres de ellos puedan conocerse, seguramente esta información hará que la comunicación interna resulte una herramienta efectiva y confiable para luego poder alcanzar el posicionamiento deseado en el mercado por parte de la organización.

\section{Mercadotecnia del sentido de la misión}

Un aporte más para abordar y desentrañar la cuestión de la comunicación en las empresas, el endomarketing que resulta muchas veces contradictorio entre la teoría y la puesta en práctica del mismo, mencionaremos a Kotler (1998) y su aporte a través de la mercadotecnia del sentido de la misión que:

...significa que la compañía debe definir su misión en términos sociales amplios, más que en los términos limitados del producto. Cuando una compañía define una misión social, los empleados se sienten mejor acerca de su trabajo y tienen un sentido más claro de la dirección. (Kotler, 1998, p. 576)

En este sentido el autor menciona el ejemplo de varias empresas que tienen en común un pensamiento, una filosofía con la cual expresan “... somos responsables hacia nuestros empleados, los hombres y mujeres que trabajan para nosotros en todo el mundo. Debemos considerar a todos como individuos, debemos respetar su dignidad y reconocer sus mérito" (Kotler, 1998 , p. 576) 
Para ello estas organizaciones invierten tiempo en investigar, observar, escuchar y evaluar aquello concerniente a su personal. Las empresas son las encargadas desde su génesis de fomentar y transmitir entre su gente los códigos y los basamentos éticos a seguir. Kotler (1998) manifiesta que "en cualquier empresa la conducta ética debe ser una tradición, una forma de hacer negocios que se transmite de generación en generación de empleados, en todos los niveles de la organización" (Kotler, 1998, p. 583) Es en este aspecto que toda organización debería hacer foco, sin duda el prestigio alcanzado puertas afuera ha tenido origen en el interior de la empresa, habiendo comunicado con claridad y solvencia los puntos claves para que el personal se sienta que cuenta con las herramientas suficientes para encarar el trabajo diario.

\section{Las crisis en las pequeñas empresas}

La comunicación en momentos de crisis nos sitúa ante un desafío adicional al que enfrentarse: la posibilidad latente de la pérdida de valor de las empresas. El desgaste del vínculo comercial que mantenemos con nuestros clientes, y lo que es más preocupante, la incertidumbre de qué pasará con ellos, preguntándonos si seguirán consumiendo nuestros productos o servicios, a qué precio, bajo qué condiciones, durante cuánto tiempo. Para afrontar los diferentes estados de situación los primeros pasos a seguir parten desde el interior de la organización. A continuación algunos lineamientos:

- Preparar a los directivos de la empresa para afrontar la crisis

- Aprender a gestionar los miedos.

- No dejarse llevar por el desencanto

- Lograr confianza en nosotros mismos y en nuestras personas.

- Trabajo en equipo descubriendo fortalezas y debilidades.

- Conocer las inquietudes, dudas y necesidades del personal de la empresa.

- Compartir problemáticas sobre casos puntuales experimentados por los empleados.

- Reunir el máximo de información posible.

- Establecer el formato de la comunicación (reuniones, conferencia de prensa, gacetillas)

- Focalizarse en el cliente y en sus necesidades

- Lograr un mensaje que de cuenta del modo de vida de los clientes.

- Definir el perfil de los clientes, dónde están y cómo piensan.

- Establecer estrategias para llegar a ellos.

- Conocer a la competencia, determinar de qué manera se trabajará para diferenciarse de ella y tomar real conocimiento del estado de crisis.

- Abordar estrategias ofensivas y defensivas para establecer qué posición tenemos en el mercado.

- Sostener una situación de liderazgo en plena crisis.

Las etapas de crisis en las empresas pequeñas y medianas obligan a establecer un plan estratégico que puedan permitirles volver a tomar vuelo rápidamente. Gironell (2009) en su libro Plan de vuelo presenta los niveles de conflictividad dentro una empresa familiar y la manera en que se decide afrontar la crisis llevando adelante la idea de " creer para ver", apostando a superar los momentos críticos en las empresas familiares, en donde se entrecruzan las lazos sanguíneos 
y las necesidades económicas. Sobre este tema existen expertos que trabajan a través de su experiencia y trayectoria en asesorar a aquellas empresas que se ven imposibilitadas de establecer una comunicación clara porque son absorbidos por sus emociones y conflictos personales. Asimismo Fernández (2009) desde su libro presenta un camino a seguir basado en la gestión y los cambios en etapas que van desde el análisis del entorno, la búsqueda de la innovación, la eficiencia y lo más importante como consecuencia de las anteriores: la ejecución. Es este punto donde se debe focalizar el proceso de comunicación interna, en la puesta en práctica de aquello que se piensa y se desea transmitir, como verdaderos valores que reflejen la imagen corporativa. Tratando de evitar las contradicciones entre lo que se dice y se hace, algo que sucede a menudo en las empresas familiares donde la gestión queda opacada por la fuerte presencia de los conflictos entre sus dueños que suelen ser hermanos, padres e hijos o primos. Sobre este tema Ingouville (2005) trata en su libro Del mismo lado la manera de resolver conflictos y apela a la no confrontación de unos contra otros, buscando transitar por el camino de la negociación para colocarse del mismo lado y superar los niveles de conflictividad que se presentan a diario en este tipo de empresas donde la comunicación se torna muchas veces imposible de sostener. El resultado de toda negociación debe crear valor, la figura del facilitador dentro de las organizaciones con este nivel de conflicto es una muy buena opción para lograr cambios que logren la permanencia y la sustentabilidad de la empresa.

\section{Cierre y reflexiones finales}

Comenzando por dar un breve panorama de lo que sucede en las empresas cuando se trata la comunicación interna y de comprender un poco más todo acto comunicativo que privilegie los intereses grupales pero sin dejar de lado los intereses individuales sostenemos que:

En las organizaciones es vital el rol del líder para lograr una buena y eficaz comunicación que incluya a todo el personal, que permita un diálogo permanente para que los empleados puedan manifestar sus dudas y certezas como también sus fortalezas y ventajas. Comprender que cada persona tiene un aporte para hacer desde su lugar de trabajo y es allí donde se dará la gran batalla: reconocer ese valor agregado que cada empleado pone a diario desde su puesto de trabajo. Si bien en lo cotidiano detectar estas cuestiones resulta complejo será necesario que la empresa designe a la o a las personas apropiadas que por su experiencia y carisma estén preparadas para trabajar codo a codo con un grupo de personas que busca el reconocimiento. En este punto la única responsable de que el empleado se sienta reconocido o tenido en cuenta es la misma organización. Sabemos de los tiempos actuales de crisis constantes, de la vorágine a la que todos estamos sometidos, todo debe resolverse de manera rápida y sin el correcto análisis muchas veces. Debido a esto se descuida la comunicación y se desconoce qué sucede con aquellos que tienen en sus manos la realización de diversas tareas que forman parte del engranaje de toda organización. En tal sentido se trata de obtener el tan mencionado pero no siempre logrado sentido de pertenencia por parte de los empleados. Aquí es donde el accionar de la compañía deberá poner su empeño, buscar un compromiso que sólo se logrará si se comunica con la verdadera intención de llevar adelante una tarea de campo ardua y sostenida en el tiempo. Como vimos en los ejemplos citados anteriormente el tratamiento de la comunicación es importante para luego ver resultados que puedan medirse, cuantificarse en cuanto a niveles de 
calidad. La empresa refleja en su exterior aquello que le sucede a diario en su interior. Muchas veces se arriba a resultados negativos y se desconoce el motivo que da origen a esta situación, pero al momento de indagar con un consultor la empresa corrobora que se ha descuidado la comunicación entre su gente, partiendo a la empresa, ubicándola en un estado de situación complicado y dividido entre lo que sucede puertas adentro y la demanda del exterior. La interacción debe ser constante para que en los momentos de mayor incertidumbre se pueda salir adelante, sobre todo en los momentos de crisis que es cuando surgen las preguntas y se esperan respuestas mágicas que no llegan. Un consultor debe muchas veces indicar y establecer aquello que no se hizo durante largo tiempo en una organización, lo cual supone barajar y empezar de nuevo. Y es aquí donde se presentan los mayores conflictos: reconocer lo que no se hizo y comenzar a desarrollarlo, a través de establecer internamente la estrategia comunicacional a seguir, puntualizando la definición de objetivos, determinar la estrategia y los tiempos de todo el proceso. Dejando de lado el hermetismo, integrando ideas y conceptos, respetando la trayectoria e historia de la organización y de sus dueños-directivos pero siempre trabajando con la premisa de que esta trayectoria e historia tienen sentido gracias a que el personal aportó día a día su trabajo. Es en ellos -los empleados-y por ellos que se necesita recurrir a una comunicación sin prejuicios ni falsos temores, en búsqueda de un camino más integrador que posibilite comunicar bien para negociar mejor.

\title{
Referencias Bibliográficas
}

Fernández, J. (2009). Gestión en tiempos de crisis. Barcelona: Editorial Deusto

Gironell, M. (2009). Plan de vuelo. Barcelona: Editorial RBA Libros SA

Goffman, E. (1994). Actuaciones. Buenos Aires: Editorial Amorrortu.

(1970). Interaccion rituals. Buenos Aires: Editorial Tiempo Contemporáneo.

Ingouville, F. (2005). Del mismo lado. Barcelona: Editorial Grijalbo.

Kotler, P. y Armstrong, G. (1998). Fundamentos de Mercadotecnia. México D. F.: Editorial Prentice-Hall Hispanoamericana S.A.

\begin{abstract}
Summary: Thinking about what it means for a company having its personnel trained comes up more questions than answers. Finding the right people, choosing the period when is more likely to take time to train people in terms of avoiding lacks in profitability or planning how much to invest are issues that corporate managers should plan carefully. In addition, the idea to apply internal marketing strategies raise at the same time. It's time for the company to explore, understand, deepen and implement those values, virtues, strengths and disadvantages. In order to reverse and turn them into positives.
\end{abstract}

Keywords: communication plan - differentiation - endomarketing - image and corporate identity - individual and group interests - internal communication - management attitudes - role of the leader - staff training. 
Resumo: Quando pensamos em termos do que para uma empresa implica a capacitação de seus empregados aparecem mais dúvidas que certezas. Encontrar aos profissionais adequados, em que momento ou época do ano é mais provável destinar tempo para formar a nossa gente e que isto não implique uma baixa na rentabilidade da empresa devido a que os empregados não estão nos postos de trabalho como fazem normalmente, quanto se deverá inverter para isso, etc. São questões que os gerentes das empresas devem planificar numa voragem que os abstrai e concentra ferozmente, e os retira da toma de decisões. Junto a estas questões, surge a idéia de fazer um trabalho de marketing interno, portas para dentro. É hora de indagar, conhecer, aprofundar e colocar em prática aqueles valores, virtudes, acertos, fortalezas e desvantagens da empresa, as quais se deverão trabalhar para reverter e converter em aspetos positivos.

Palavras chave: capacitação dos empregados - comunicação interna - diferenciação - endomarketing - gestão das atitudes - imagem e identidade corporativa - interesses individuais e grupais - plano de comunicação - rol do líder. 